\title{
YBaviren
}

\section{Board of advisors for new Institute}

The VanAndel Institute (Nature Medicine 2, 842), which will likely one day rival the well-known Howard Hughes Medical Institute, took a step in that direction late last year in announcing its first Board of Scientific Advisors. The board will consist of five notable scien-

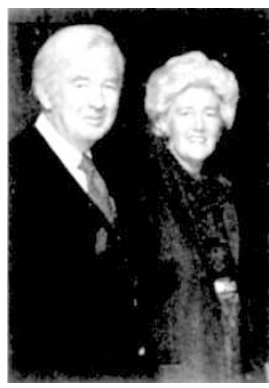

Jay and Betty Van

Andel, founders of the new research Institute. tists: Michael S. Brown, chairman of the board and director of the Center for Medical Genetics at the University of Texas Southwestern Medical School, Richard Axel of the College of Physicians and Surgeons at Columbia University, Joseph L. Goldstein, also at Texas Southwestern, Daniel Nathans of the Johns Hopkins University School of Medicine, and Phillip A. Sharp of the Massachusetts Institute of Technology. Over the next three years, these scientists will develop "a long-range strategic plan to help determine and evaluate the Institute's future direction and areas of medical research."

\section{FDA approves drug to treat diabetes}

An advisory committee of the US Food and Drug Administration (FDA) has recommended that the agency approve a new diabetes drug that would be the first to directly treat insulin resistance, the underlying cause of type II diabetes, which afflicts 16 million people in the The drug, Rezulin, known chemically as troglitazone and developed by Parke-Davis, someUnited States, and millions more worldwide. how resensitizes the body to insulin, a hormone that converts blood sugar into energy. Although the FDA is not bound by advisory panel decisions, it usually follows them.

Type II diabetes strikes mostly individuals older than 40, many of whom are unaware that they have the disease, and accounts for nearly 95 percent of all diabetes cases. Unlike type I diabetes, in which the body cannot

\section{Just in TIME}

After a year of hopeful, though often sensationalized, news in the fight against AIDS, the editors of TIME magazine have named a leading US AIDS researcher, David Ho, director of the Aaron DIamond AIDS Research Center in

Although it is a only an honorary title, the citation is usually given to world political leaders or other highprofile individuals. The last time it was given to a scientist was 1960 , when TIME recognized 15 scientists from different disciplines as the "Men of the Year," saying that 1960 ushered in a "renaissance" in scientific knowledge.

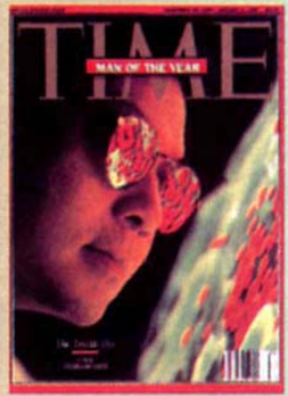

Ho was characteristically humble about this latest honor, lauding the contributions of his co-workers at Aaron Diamond as well as "many other outstanding scientists and institutions active in HIV/AIDS research."

\section{India turns the worm}

The new year brings some good health news to India: After a 12-year battle, 1997 may be the year India will be free of guinea worm disease (GWD), also known known as "dracunculiasis."

When the National Institute of Communicable Diseases

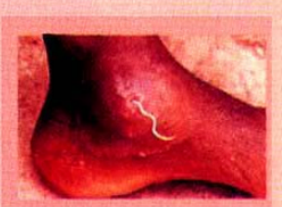
(NICD) launched its guinea worm eradication program in 1984, GWD was endemic in 12,840 villages in seven states, and there were an estimated 40,000 patients. By 1995 , cases dropped to 60 , and the disease was confined to 24 villages in three districts of Rajasthan. "With tight surveillance ... we are sure that the country will be rid of GWD from 1997 on," says one NICD official.

Although not fatal, GWD is a debilitating water-borne disease spread by "cyclops," a tiny water flea that acts as host to larvae of the nematode Dracunculus medinensis. Infected cyclops release the larvae in exposed humans, and the larvae grow over a period of months into adult worms that can measure a meter long. Victims fall ill when the worm tries to seek its way out through the skin, causing ulcers.

Even though help came initially from the World Health Organization, GWD is the first disease to be wiped out almost entirely by Indian efforts. The official says success came from a three-pronged strategy: converting "step" wells into "draw" wells to prevent water coming into direct contact with infected persons, chemical treatment of well water to kill the cyclops, and supplying drinking water filters to individual homes.

In the absence of a cure, people infected by guinea worms were treated by traditional healers, who located the worm under the skin, made a small incision at the spot, and pulled the worm out. With the disease no longer a threat in India, the global campaign against GWD is focused on a few remaining pockets in the African continent.

K.S. JAYARAMAN New Delhi, India make insulin, type II is a metabolic disorder that results from the body's inability to either make enough insulin or to properly use it.

Rezulin stimulates a gene to produce more insulin-controlled proteins that in turn remove glucose from the bloodstream, essentially giving insulin more opportunity to do its job. Most adult-onset diabetics control their disease through diet, exercise and medications that increase insulin production and decrease glucose production, but eventually many of them will require insulin shots during the later stages of their disease. Researchers hope that Rezulin can decrease, or possibly even eliminate, the need for insulin injections.

"This drug is a breakthrough; it is unbelievable," said Steven Edelman, an endocrinologist with the University of California at San Diego and one of the researchers involved in clinical trials of the drug. Edelman is also a type II diabetic. Patients treated with Rezulin were able to reduce their daily insulin dose by 58 percent, and 15 percent of patients in the treatment group were able to discontinue insulin therapy by the end of the study.

Researchers believe the drug to be safe, but studies show that there are side effects, including headaches. Also, in animal studies, the drug increased the size of rodents' hearts, apparently through fluid retention. Although researchers have seen nothing similar in humans - nor in monkeys and dogs given the drug - the FDA advisory panel urged long-term monitoring, and recommended that it not be used by heart disease patients.

MARLENE CIMONS Washington, $D C$ 